\title{
Ontogeny of microhabitat use and two-step recruitment in a specialist reef fish, the Browncheek Blenny (Chaenopsidae)
}

\author{
P. A. Hastings • G. R. Galland
}

Received: 8 June 2009/ Accepted: 27 October 2009/Published online: 27 November 2009

(C) The Author(s) 2009. This article is published with open access at Springerlink.com

\begin{abstract}
Ecological specialization is common on coral reefs and almost certainly contributes to the high diversity of fishes and invertebrates associated with reefs. Here, the recruitment pathway of an endemic Gulf of California fish, the Browncheek Blenny, Acanthemblemaria crockeri (Teleostei: Chaenopsidae), which specializes as an adult on vacant invertebrate tests or tubes, is reported. Like most reef fishes, Browncheek Blennies have a planktonic larval stage that leaves the reef and later settles on suitable habitat as a fully developed juvenile. These blennies follow a clear, "two-step" recruitment pathway, however, and do not reside in invertebrate tests until reaching an adult body size. Individual juveniles and adults were observed for 3 min intervals in order to develop average time budgets for this species. Members of both sexes and all post-settlement life-history stages were included in the analysis. The difference in habitat use by post-settlement juveniles and adults is striking; the average juvenile spends none of its time inside a test, and the average large adult spends all of its time inside a test. Using data on intermediate-sized individuals, the behavioral change associated with invading a test was determined to be size-cued, and it occurs between 20 and $30 \mathrm{~mm}$ standard length. Changes in feeding and predator avoidance behaviors are also associated with the ontogenetic shift from life in the open to life in a shelter. Addition of artificial shelters demonstrated the essential role of access to this specialized resource in the
\end{abstract}

Communicated by Biology Editor Dr. Philip Munday

P. A. Hastings $(\varangle) \cdot$ G. R. Galland

Marine Biology Research Division, Scripps Institution

of Oceanography, University of California San Diego,

9500 Gilman Dr., La Jolla, San Diego, CA 92093, USA

e-mail: phastings@ucsd.edu population regulation of adults but not juveniles of these blennies.

Keywords Habitat use - Resource limitation . Feeding rate · Ontogeny · Predation risk · Chaenopsidae . Gulf of California

\section{Introduction}

Coral reefs are highly heterogeneous ecosystems that support a high diversity of fishes and invertebrates. Ecological specialization and microhabitat use have been shown to contribute to this high diversity and to resource partitioning, especially among reef fishes (Sale 1977; Bellwood et al. 2006). Specialists often bear a cost of reduced ability to use alternate resources (Caley and Munday 2003; but not always: see Lawlor and Maynard Smith 1976; Robinson and Wilson 1998) and therefore may be especially vulnerable to resource limitation and ecosystem change. Generalists, by definition, are able to use a wider range of resources (Futuyma and Moreno 1988). Within coral reef fish assemblages, there are numerous species that live in specialized microhabitats in and on the reef complex (Munday and Jones 1998).

Most reef fishes, including specialists, have a larval stage that leaves the reef (Sale 1980; Doherty and Williams 1988). The pathway that these fishes follow to come to occupy their adult reef niches is well known for many generalists (e.g., Williams and Sale 1981; Wellington 1992; Öhman et al. 1998) and some conspicuous specialists (e.g., anemone fishes, see Elliott et al. 1995; Elliott and Mariscal 2001; Buston 2003). The ontogenetic shift from planktonic larvae to juvenile nurseries to adult niches, that many reef fishes undertake, is partly dictated by changing environmental interactions that they experience during a 
severalfold increase in size from larvae to adults (Leis 1991). Some aspects of this shifting role, or so-called "ontogenetic niche," are well documented for fishes, including changes in food habits (Gerking 1994) and changes from planktonic larvae to benthic juveniles (Sale 1980; Doherty and Williams 1988; Kaufman et al. 1992). Additionally, the transition from juvenile to adult habitats has been shown to be an important transition in some reef fishes (Jones 1984; Lecchini and Galzin 2005).

Recently, there has been a growing recognition of the importance of small-bodied cryptobenthic fishes in reef ecosystems, and many of these small fishes are microhabitat specialists (Munday and Jones 1998). Though they have historically been underrepresented in reef diversity and biomass studies (due to their small size and difficulty in field identification), cryptobenthic fishes are significant contributors to reef microcarnivory and detritivory (Kotrschal and Thompson 1986; Depczynski and Bellwood 2003) and constitute a significant portion of reef fish biodiversity (Smith-Vaniz et al. 2006). Many of these less conspicuous specialists almost certainly follow a similar "two-step" recruitment path, but few data are available documenting this transition (Munday and Jones 1998; Gonçalves and Faria 2009).

Here, the ontogeny of microhabitat use in a small-bodied, ecological specialist, the Browncheek Blenny, Acanthemblemaria crockeri Beebe and Tee Van (Teleostei: Chaenopsidae) is documented and the role of adult microhabitat in limiting population density is examined experimentally. Like most other chaenopsids, the Browncheek Blenny is a microhabitat specialist, occupying vacant burrows or tests of invertebrates on reefs (Hastings 1988). These shelters serve as refuges from predators (Hastings 1991) and as egg-deposition sites (Hastings 1986). The Browncheek Blenny is endemic to the Gulf of California (Stephens 1963; Lin et al. 2009), and its early life history is similar to that of most other small benthic reef fishes (Thresher 1984; Miller 1984; Munday and Jones 1998; Depczynski and Bellwood 2006), i.e., eggs deposited on the substrate (in this case inside shelters) are guarded by the resident male until hatching (Hastings 1988), when the larvae enter the plankton to later settle on hard substrates. In the central Gulf, Browncheek Blennies breed from early spring through at least May (Hastings 1988) and grow to at least $50.5 \mathrm{~mm}$ SL (Stephens 1963). Recent genetic studies have shown that two cryptic species of Browncheek Blennies occur within the Gulf; the population studied here is the "Gulf form" (Lin et al. 2009).

\section{Materials and methods}

This study was conducted along a rock ledge on the eastern side of Bahia San Carlos in the central Gulf of California,
Sonora, in spring and summer of 1984. This bay is well protected and generally subject only to relatively weak tidal currents. The substrate sloped gently from a steep rocky shoreline and was composed of rock and small boulders that gave way to sand and cobble substrate at 4-5 m depth. Hard substrates were encrusted with numerous species of algae, sponges, and ascidians, as well as colonies of the coral Porites californica Verrill. Both living and dead coral heads were inhabited by the mollusks Lithophaga aristata (Dillwyn) and Serpulorbis sp. Vacant burrows of the former, and tubes of the latter, were often occupied by Browncheek Blennies (Hastings 1988; Fig. 1). Large boulders (1-2 $\mathrm{m}$ tall, long, and wide) were also present at the study site and apparently resulted from fracture and collapse of the overhanging rock ledge. The encrusting benthic community of the upper surface of these boulders was similar to that of the surrounding reef flat.

\section{Focal observations of blennies}

The microhabitat use by Browncheek Blennies was quantified by observing individual animals while snorkeling. Focal blennies showed no obvious reaction to the observer who maintained a distance of at least $1.5 \mathrm{~m}$ from subjects. Prior to focal observation intervals, individuals were scored as resident (in a shelter; Fig. 1) or nonresident (in the open) and their sex and body size were recorded (small [15$19 \mathrm{~mm}$ standard length (SL)]; medium [20-30]; or large [ $>30]$ ). The size range of individuals observed in this study was 15-49 mm SL. Sex was determined using lateral body coloration. Female Browncheek Blennies have a series of mid-lateral blotches, while males have several rows of light spots on a dark background (Stephens 1963; Lindquist 1985; Lin et al. 2009); the anterior portion of the body bearing blotches in females was visible on all focal individuals included in this study. Most individuals $<20 \mathrm{~mm}$

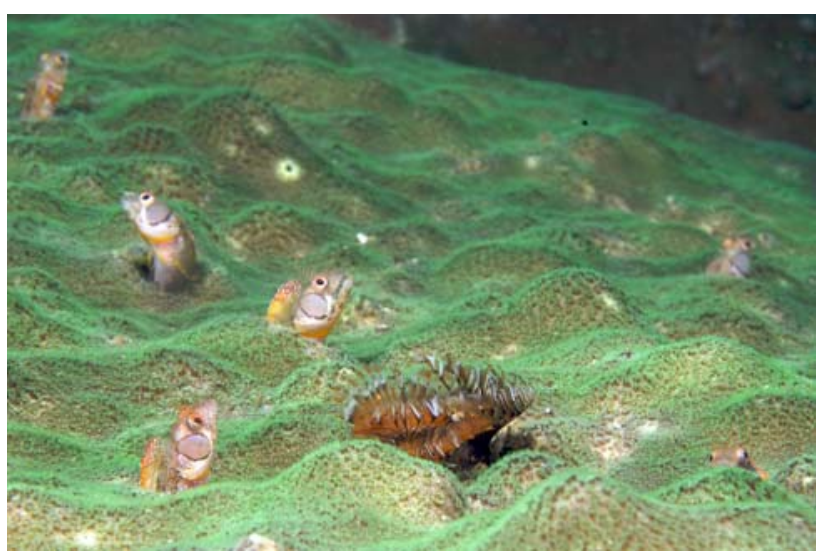

Fig. 1 Resident Browncheek Blennies (Acanthemblemaria crockeri) in natural shelters (photo by Octavio Aburto) 
SL typically do not express sex-specific coloration, so all "small" individuals were classified as "juveniles." Focal individuals were observed for 3 min intervals during which the amount of time spent in a shelter and in the open (mutually exclusive categories) and the number of feeding bites taken both on the substrate and in the water column were recorded. Because focal individuals were selected in part to maximize the number of sample points in size and sex categories, sample sizes do not reflect relative abundances at the study site.

\section{Blenny densities and shelter additions}

The effect of shelters on the densities of resident (in a shelter) and nonresident (outside of a shelter) Browncheek Blennies was studied on the reef flat and on boulder tops. On the reef flat, two permanent transects were established at a depth of 1.5-3 m. The number of resident and nonresident blennies was counted in each of $281 \mathrm{~m}^{2}$ quadrats. Quadrats on adjacent sides of the transect lines were randomly assigned to either the experimental or control group. Twenty-eight Porites coral heads without resident blennies or apparent shelters were selected from an adjacent reef area, and one coral head was added to each quadrat. Intact coral heads were added to the control quadrats, while experimental quadrats received coral heads to which two artificial shelters had been added by inserting 1.5-dram glass vials into holes drilled on opposite sides of head. This was done in conjunction with a study on the reproductive success of individual males (Hastings 1988).

Fourteen large boulders adjacent to the reef flat were numbered, measured for upper surface area, and surveyed for resident and nonresident Browncheek Blennies. Nine boulders, averaging $1.7 \mathrm{~m}^{2}$ in area $(\mathrm{SD}=1.0$, range $=$ 0.6-3.4), were arbitrarily assigned to the experimental group while the remaining five, averaging $2.0 \mathrm{~m}^{2}$ $(\mathrm{SD}=1.0$, range $=0.7-3.4)$, were assigned to the control group. Between one and four, 1.5-dram glass vials were added to coral heads and placed on each experimental boulder (1.6 vials $\mathrm{m}^{-2}$ ). Control boulders received coral heads without vials or apparent natural shelters.
The densities of nonresident and resident blennies were counted in experimental and control areas prior to coral head/shelter additions (23 April) and 26 days (18 May), 35 days (27 May), 46 days (7 June), 63 days (24 June), and 101 days (1 August) after additions. During each census, the numbers of juvenile and adult, resident and nonresident Browncheek Blennies were recorded and converted to number per square meter, and these data were analyzed through time using a repeated measures analysis of variance.

Predation risk

The risk of predation on Browncheek Blennies was determined in two ways. First, the number of close passes $(<0.5 \mathrm{~m})$ by a predator during each of the aforementioned 3-min focal observation periods was recorded. Second, three-min focal observations were conducted on 18 individuals of the most common predator, the Yellow Snapper, Lutjanus argentiventris (Peters). Specifically, the amount of time spent foraging (that is, actively swimming just above the bottom), on boulder tops or the reef flat, was noted, and the number of feeding bites or strikes that were observed was recorded.

\section{Results}

Focal observations of blennies

Microhabitat use by Browncheek Blennies was bimodal (Fig. 2) with some individuals spending virtually all of their time in the open and others spending all or almost all of their time within vacant invertebrate tubes. Resident blennies (those in shelters at the start of focal intervals) remained almost exclusively inside their shelters, often with only the anterior portion of their body exposed. They did, however, make occasional brief forays outside to take feeding bites. Nonresident blennies (those outside of shelters at the start of focal intervals) remained in the open and never entered a shelter. They typically perched on a coral head or algae-covered rock from which they made occasional short feeding forays.
Fig. 2 Percent time spent in a shelter by observed Browncheek Blennies (Acanthemblemaria crockeri), plotted by sex (a) and size class (b). The single individual at 51-60\% was a resident medium-sized male (a)

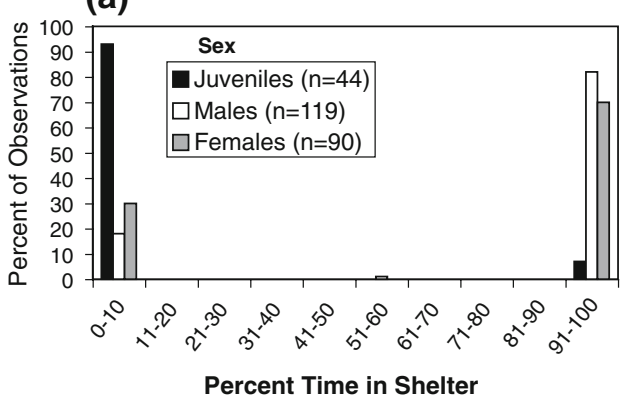

Percent Time in Shelter (b)

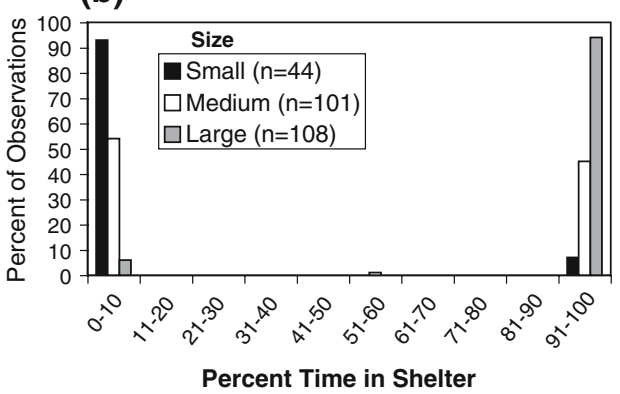


Table 1 Mean (standard deviation) percent time spent in shelters by Browncheek Blennies in Bahia San Carlos

\begin{tabular}{|c|c|c|c|c|c|c|c|}
\hline \multicolumn{8}{|c|}{ Residency status and $\operatorname{sex}^{\mathrm{a}}$} \\
\hline & & \multirow[t]{2}{*}{$N$} & \multirow[t]{2}{*}{ Percent time in shelter (SD) } & \multicolumn{4}{|l|}{$Z$} \\
\hline & & & & $\mathrm{J}$ & NRM & $\mathrm{NRF}$ & $\mathrm{RM}$ \\
\hline \multicolumn{2}{|l|}{ Juveniles (J) } & 44 & $6.8(25.4)$ & - & - & - & - \\
\hline \multicolumn{2}{|c|}{ Nonresident males (NRM) } & 21 & $0(0)$ & $0.01 \mathrm{~ns}$ & - & - & - \\
\hline \multicolumn{2}{|c|}{ Nonresident females (NRF) } & 28 & $3.4(17.9)$ & $0.09 \mathrm{~ns}$ & $0.02 \mathrm{~ns}$ & - & - \\
\hline \multicolumn{2}{|c|}{ Resident males (RM) } & 98 & 99.4 (3.9) & $8.93 *$ & $7.17 *$ & $8.04 *$ & - \\
\hline \multicolumn{2}{|c|}{ Resident females (RF) } & 62 & $99.8(0.4)$ & $8.23 *$ & $6.81 *$ & $7.56^{*}$ & $0.37 \mathrm{~ns}$ \\
\hline \multicolumn{8}{|c|}{ Body size (sexes combined) ${ }^{b}$} \\
\hline & \multirow[t]{2}{*}{$N$} & & \multirow[t]{2}{*}{ Percent time in shelter (SD) } & \multicolumn{2}{|l|}{$Z$} & & \\
\hline & & & & $\mathrm{S}$ & M & & \\
\hline Small (S) & 44 & & $6.8(25.4)$ & - & - & & \\
\hline Medium (M) & 101 & & $58.8(49.0)$ & $5.05^{*}$ & - & & \\
\hline Large (L) & 108 & & $93.3(24.7)$ & $8.45^{*}$ & $4.65 *$ & & \\
\hline
\end{tabular}

$Z$ values are from a Mann-Whitney test

Bonferroni corrected probabilities: $\mathrm{ns}>0.05 ; *<0.001$

${ }^{a}$ Residency status and sex. $\mathrm{RM}=$ resident males (residents occupied a shelter at the beginning of focal intervals); RF $=$ resident females; $\mathrm{NM}=$ nonresident males (nonresidents were in the open at the beginning of focal intervals); $\mathrm{NF}=$ nonresident females

${ }^{\text {b }}$ Size class. $\mathrm{S}=$ small $(<20 \mathrm{~mm} \mathrm{SL}) ; \mathrm{M}=$ medium (20-30); $\mathrm{L}=$ large ( $\left.>30\right) . N=$ number of 3-min focal intervals

This pattern of differential microhabitat use was related to body size, not sex. Males and females were common in both resident and nonresident behavioral classes (Fig. 2), and within these classes, the sexes did not differ in percent time spent in a shelter (Table 1). In contrast, the size categories were disproportionately represented in the two behavioral classes. More than $90 \%$ of all small individuals (juveniles) spent none of their time in shelters; more than $90 \%$ of large adults spent all of their time inside a shelter, and similar proportions of medium-sized individuals spent either all or none of their time in shelters (Fig. 2). In other words, the obtainment and defense of a shelter increase with size (= growth; Table 1).

Nonresident blennies fed at a significantly higher rate than residents (Table 2). This difference was unrelated to body size: small nonresidents took on average 2.54 bites $3 \min ^{-1}(N=41)$, while medium-sized nonresidents took 2.58 bites $(N=40 ; P>0.05$, Mann-Whitney test). Nonresidents took significantly more feeding bites from the water column, while residents fed more often from the substrate (Table 2).

Blenny densities

\section{Nonresidents}

The results of nonresident density monitoring revealed a clear recruitment pulse at the study site and confirmed that juvenile blennies occurred in the same habitat as adults, often residing within a few centimeters of occupied shelters. On the reef flat, juveniles were absent at the beginning of the study (Fig. 3a), began appearing by the second census period (18 May), reached a maximum average density of just under $1 \mathrm{~m}^{-2}$ by census period four (7 June), and declined to nearly $0 \mathrm{~m}^{-2}$ at the end of the study (1 August). These new recruits increased in size and attained adult coloration within a few weeks. As a result of this reclassification, adult nonresident densities showed a similar, but lagged, peak in abundance behind that of juveniles. Nonresident adults were absent at the start of the monitoring, reached their highest densities by census period 5 (24 June), and declined sharply by the last census (1 August).

A similar pattern was observed on the boulder tops (Fig. 3b): juveniles were absent at the beginning of the

Table 2 Frequency and location of feeding bites by nonresident and resident Browncheek Blennies

\begin{tabular}{llll}
\hline & Nonresidents & Residents & $P$ \\
\hline$N$ & 90 & 163 & \\
Bites off substrate & $1.6(1.6)$ & $0.3(0.6)$ & $<0.001$ \\
Bites on substrate & $0.8(0.9)$ & $1.4(1.4)$ & $<0.05$ \\
Total bites & $2.4(1.9)$ & $1.7(1.5)$ & $<0.001$ \\
\hline
\end{tabular}

Mean number of bites per 3-min focal interval (SD). Probability values are Bonferroni corrected from a Mann-Whitney test 
(a)

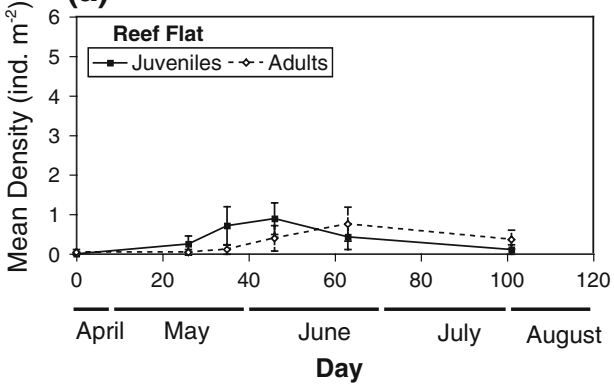

Fig. 3 Mean density of nonresident juvenile and adult Browncheek Blennies (Acanthemblemaria crockeri; with 95\% confidence intervals) on the reef flat (a) and on boulder tops (b) through time. Sample

study, reached a peak density by census period 4 , and declined by the final census. As on the reef flat, the peak density of nonresident adults on the boulder tops occurred one census period after that of juveniles. During peak abundances, average densities of nonresidents on boulder tops were more than twice those observed on the reef flat (Fig. 3a, b).

The addition of shelters to experimental plots had no statistical effect on nonresident densities on the reef flat or boulder top habitats (Table 3 ). A repeated measures analysis of variance of nonresident densities for combined control and experimental sites indicated a significant effect of time $\left(F_{(5,257)}=20.8, P<0.001\right)$, confirming that total density peaked after an initial recruitment pulse and then subsequently declined over the remaining census periods, and habitat $\left(F_{(1,260)}=25, P<0.001\right)$, confirming the higher observed densities on the boulder tops compared with the reef flat, and a significant interaction $\left(F_{(5,257)}=11\right.$, $P<0.001$ ), implying a difference in the dynamics of nonresident densities at the two habitats (Fig. 3a, b).

\section{Residents}

Artificial shelters were readily used by both male and female Browncheek Blennies and were even suitable as egg-deposition sites (Hastings 1988). Addition of coral colonies with these available shelters led to a significant increase in resident Browncheek Blenny density on both the reef flat and the boulder tops when compared to the control treatment of adding corals with no shelters (Table 3). A positive relationship was seen between time and density in both habitats (Table 3). The interaction between time and shelter addition was significant on the reef flat (Table 3), implying that the increase in density associated with shelter addition had a significant time component (i.e., a delay; Fig. 4). There was no significant interaction between time and shelter on the boulder tops (Table 3) indicating that shelter addition had already

\section{(b)}

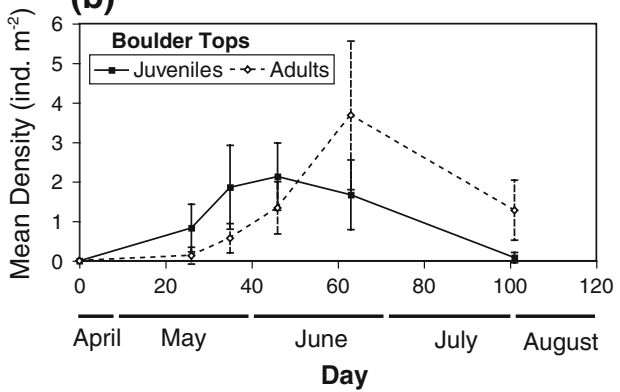

size for the reef flat $=28$ and for boulder tops $=14$. Months of the year are given for context

Table 3 Repeated measures ANOVAs for effects of shelter additions on densities of nonresident and resident Browncheek Blennies on the reef flat (14 control and 14 experimental quadrats) and boulder tops ( 9 experimental and 5 control boulders)

\begin{tabular}{lrrr}
\hline & $d f$ & $F$ & \multicolumn{1}{l}{$P$} \\
\hline Nonresidents: reef flat & & & \\
Time & 5 & 1.30 & $<0.001$ \\
Treatment & 1 & 1.26 & 0.265 \\
Interaction & 5 & & 0.284 \\
Nonresidents: boulder tops & 5 & 13.33 & \\
Time & 1 & 0.18 & $<0.001$ \\
Treatment & 5 & 0.74 & 0.677 \\
Interaction & & & 0.599 \\
Residents: reef flat & 5 & 7.11 & \\
Time & 1 & 3.37 & 0.012 \\
Treatment & 5 & & 0.007 \\
Interaction & & 9.18 & \\
Residents: boulder tops & & 6.38 & 0.001 \\
Time & 5 & 1.87 & 0.113 \\
Treatment & 1 & & \\
Interaction & 5 & &
\end{tabular}

affected resident density by the first post-addition census (Day 26; Fig. 4).

\section{Predation risk}

In Bahia San Carlos, the risk of predation was greater on the reef flat than on boulder tops. First, the number of passes by predators within $0.5 \mathrm{~m}$ of focal blennies was more than an order of magnitude greater on the reef flat. The mean number of passes per 3-min focal interval was 0.69 on the reef flat $(\mathrm{SD}=0.49, N=36)$ and 0.05 on the boulder tops $(\mathrm{SD}=0.10, N=39 ; P=0.02$, MannWhitney test). In other words, an average Browncheek Blenny on the reef flat experienced a close pass by a predatory fish every 4.5 min while an average blenny on a 
(a)

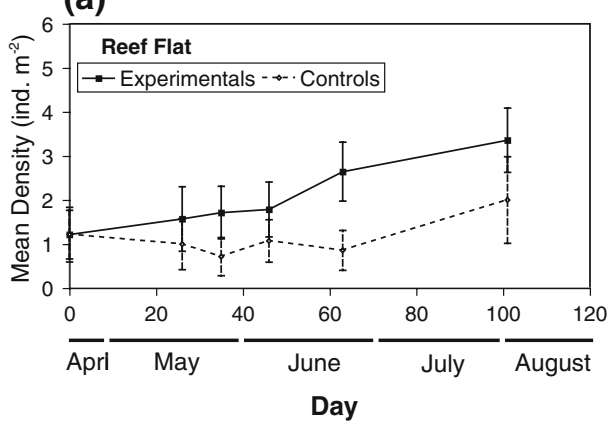

(b)

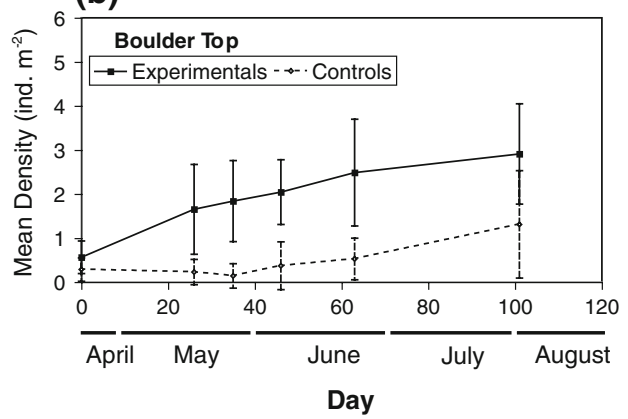

Fig. 4 Mean density of resident Browncheek Blennies (Acanthemblemaria crockeri; with 95\% confidence intervals) in control and experimental reef flat quadrats (a) and boulder tops (b) through time. Months of the year are given for context

boulder top experienced a close pass every $60 \mathrm{~min}$. Second, focal observations of the most conspicuous predator, the Yellow Snapper, revealed that this species spends most of its time foraging over the reef flat. Observed Yellow Snappers spent on average $68.4 \%$ of their time foraging on the reef flat $(\mathrm{SD}=21.6)$ and only $3.1 \%$ of their time foraging on the boulder tops ( $\mathrm{SD}=4.6 ; N=18 ; P<0.01$, Mann-Whitney test). These individuals also took significantly more bites on the reef flat (mean $=1.3$ bites $3 \mathrm{~min}^{-1}, \mathrm{SD}=1.3$ ) than on the boulder tops (mean $=0.6$ bites $3 \mathrm{~min}^{-1}, \mathrm{SD}=0.2 ; P<0.01$, Mann-Whitney test). Strikes by snappers appeared to be directed toward organisms that had been startled by their rapid swimming. During close passes by predators, resident Browncheek Blennies withdrew into their shelter while nonresidents remained motionless. No successful strikes by predators on blennies were observed.

\section{Discussion}

Ontogeny of microhabitat use

The results of the time budget and density surveys clearly show that Browncheek Blennies follow a "two-step" recruitment pathway, with larvae, juveniles, and adults all filling distinct niches. The first step involves the settling of planktonic larvae onto hard substrates on the reef surface, in the same general vicinity as tube-dwelling adults (residents). In Bahia San Carlos, this step took place mostly during June and July, when a distinct pulse in numbers of juveniles was observed (Fig. 3). These juveniles initially spent all of their time as nonresidents. They did not recruit directly to tubes but instead spent at least a few weeks in the open, utilizing different behavioral strategies in predator avoidance and prey capture than their nearby adult counterparts (see below). During these weeks, juveniles grew and developed sex-specific coloration, but remained in the open for some time, as indicated by the lagged peak in nonresident adult abundance observed at the site (Fig. 3). Both morphologically distinct males and females were observed living as nonresidents (Fig. 2), supporting the hypothesis that neither sex nor development of dimorphic coloration is associated with the second step of the recruitment pathway. This step occurs when individuals leave the open reef environment and enter vacant invertebrate tests that are known to be important for reproductive success (Hastings 1988). Our time budget data show that this transition is size-mediated (Fig. 2). An average individual of less than $20 \mathrm{~mm}$ SL spent all of its time in the open, and an average individual of more than $30 \mathrm{~mm} \mathrm{SL}$ spent all of its time in a shelter, implying that the cue to leave the open and enter a shelter occurred between these sizes. This implication is supported by our observations that intermediate-sized individuals $(20-30 \mathrm{~mm} \mathrm{SL})$ lived as nonresidents and residents in similar proportions (Fig. 2).

While habitat use is the most striking ontogenetic shift in the Browncheek Blenny niche, it is not the only change. Two further differences between juvenile and adult niches are the means with which they escape predation and their feeding behavior. Nonresident blennies rely on crypsis for avoiding predation. During the time budget surveys of Browncheek Blennies and Yellow Snappers, nonresident blennies were consistently observed remaining perfectly motionless during close passes by predators, a behavior reported for other chaenopsids (Hastings 1991). This strategy contrasted with resident adults, which simply retreated into their shelters whenever startled or threatened. Both methods proved effective, as we never witnessed a successful attack on a Browncheek Blenny.

Furthermore, our time budget surveys revealed a significant difference in feeding strategy between nonresidents and residents in both the rate and location. Nonresidents fed significantly more frequently than residents and more often on items from the water column, rather than from the substrate (Table 2). Residents may have been constrained to feeding primarily from the safety 
of their shelters rather than from the water column, while nonresidents typically made short upward swimming bursts, returning quickly to the bottom. This may be related to predation intensity at this site or to reduced availability of passing plankton in the protected waters of Bahia San Carlos where strong currents were rare. The relative success of these two feeding strategies and the types of prey consumed were not assessed, but this ontogenetic shift in feeding strategy of the Browncheek Blenny may contribute to it having the highest observed feeding diversity among 34 Gulf of California blennioid species (Kotrschal and Thompson 1986).

\section{Effects of predators}

The spatial distribution of Browncheek Blenny recruits was not uniform in Bahia San Carlos. The density of juvenile (and total nonresident) blennies was significantly higher on boulder tops than on the intervening reef flat. Because predatory fishes were more common and more active on the reef flat, the observed distribution of juvenile Browncheek Blennies is consistent with the hypothesis that predators impact their recruitment (to the reef, to the shelters, or both). Spatial variation in recruitment is common in reef fishes (e.g., Jones 1984; Sale et al. 1984; Cowen 1985; Doherty 1987; Forrester 1990), and predators have been implicated in this variation for some species (e.g., Tupper and Juanes 1999; Albins and Hixon 2008). However, the proximate cause of this difference in abundance of juvenile Browncheek Blennies in the two habitats is unknown. The higher density of juveniles on boulder tops could result from preferential settlement there, higher predation rates on the reef flat where predators are more common, migration from reef flat to boulder tops by post-settlement juveniles, or some combination of these. While high nonresident Browncheek Blenny densities on boulder tops may not be expected to affect reproduction (nonresidents do not reproduce; Hastings 1988), resident male reproductive success has been shown to be significantly higher on boulder tops than on the reef flat (Hastings 1988). This phenomenon could reflect an increase in feeding behavior, mating interactions, or some other activity that might be suppressed by predators on the reef flat.

\section{Shelter limitation}

Consistent with the observed ontogenetic shift in microhabitat, our results imply that shelters are not a limiting resource for juvenile Browncheek Blennies but are limiting for adults at this site in the Gulf of California. When appropriate space was created (by adding shelters), the densities of resident adults increased on both the reef flat, which had a small pool of nonresident juveniles and boulder tops, which had a larger pool of nonresidents. The relative magnitude of this increase was higher on the boulder tops, where the average increase in resident density at the end of the study (Day 101) was approximately equal to the average number of shelter additions (1.6 individuals $\mathrm{m}^{-2}$; Fig. 4). On the reef flat, the final average increase was only 1.3 individuals $\mathrm{m}^{-2}$, when compared to the consistent addition of two vials $\mathrm{m}^{-2}$ in all experimental quadrats. This difference in magnitude might be attributable to the difference in juvenile pool size between the two reef habitats, competition with other organisms that occasionally used the shelters, or both.

A further difference between the two habitats was the absence of a time component to the treatment on the boulder tops. The difference in resident density between experimental and control boulders was significant at the first post-addition census (Day 26) and held up throughout all further census periods during the study. In less than 30 days, this average difference was already nearly equal to the number of average shelter additions. On the reef flat, a consistent significant difference in resident density was not maintained until the fourth post-addition census (Day 63). The presence of this time lag on the reef flat may also reflect the difference in juvenile pool size between the two habitats (i.e., there were insufficient available nonresident juveniles to fill the shelters on the reef flat until later in the study).

Space limitation in reef fishes is predicted where prerecruitment limitation is not a dominant force (Hixon and Beets 1989; Hixon and Jones 2005) and benthic mortality rates are high, especially from predation (Shulman and Ogden 1987; Forrester and Steele 2004). This has been demonstrated in several other studies on reef fishes (e.g., Shulman 1984, 1985; Caley and St. John 1996; Forrester and Steele 2004), including other chaenopsids (e.g., Buchheim and Hixon 1992). These conditions apparently applied to this population of Browncheek Blennies as recruits were abundant and adult densities were dependent upon availability of shelters.

\section{Two-step recruitment}

"Two-step" recruitment is not unique to these blennies. Virtually all reef fishes pass through the first stage from planktonic larval populations to benthic populations (Sale 1980; Doherty and Williams 1988). Shortly after settlement, mortality rates are often high, on the order of $50 \%$ within 1-2 days of settlement in some species (Almany and Webster 2006). Under these conditions, survival between juvenile and adult niches is often dependant upon the availability of refuges from predators (Shulman 1985; Hixon and Jones 2005). Therefore, in a number of reef fish species, juveniles recruit to areas spatially distinct from 
habitats occupied by large, well-developed adults (Lecchini and Galzin 2005). For example, some apogonids recruit to patch reefs in sandy areas before moving to adult habitats on the reef slope (Finn and Kingsford 2005). Ontogenetic movement between distinct habitats is especially conspicuous among many large reef fishes such as groupers and snappers (e.g., Eggleston 1995; Dahlgren and Eggleston 2000). This has led to the recognition of the importance of distinct nursery areas such as mangroves and seagrass beds as predation refuges for juvenile reef fishes (Nagelkerken et al. 2002; Gillanders et al. 2003; Aburto-Oropeza et al. 2008).

Browncheek Blennies, unlike the aforementioned species with isolated nursery areas, are similar to some other reef fishes in that juveniles live among and around adults. Notable among these are damselfishes where interactions among juveniles and adults are relatively well studied (e.g., Sweatman 1983, 1985; Jones 1987). However, the recruitment pathway of Browncheek Blennies is unique in that it seems to be operating in the reverse of the welldescribed pattern of refuge seeking by juveniles (Shulman 1985; Hixon and Jones 2005). This pattern reflects the importance of (and dependence on) shelters for adult reproductive success in chaenopsids, not just as a means of escape from predation (Hastings 1988, 2002).

\section{Costs of microhabitat specialization}

Ecological specialists often carry the cost of reduced ability to use alternate resources (Futuyma and Moreno 1988), especially those species with morphological adaptations to their niche. Chaenopsids exhibit several apparent adaptations associated with the use of vacant invertebrate tests, including the loss of scales and loss of the lateral line on the body (Stephens 1963; Hastings and Springer 1994). These morphological features may represent phylogenetic constraints associated with specialization (Futuyma and Moreno 1988), in the sense that these character states were inherited from ancestors and may reduce an individual's ability to survive outside of a shelter. Furthermore, the significant decline in feeding rate associated with moving to a shelter could have implications for Browncheek Blenny success, through a sacrifice of maintenance, growth, and reproduction. The typical ontogenetic trajectory of chaenopsids, however, provides an opportunity for release from these constraints via retention of juvenile behaviors (dwelling in the open where feeding rates are higher) and features (cryptic coloration) as documented for females of the genus Coralliozetus (Hastings 2002). Males of these chaenopsids are constrained to make the ontogenetic transition to occupy the specialized microhabitat of shelters because these are sites of egg deposition and defense (Hastings 1986). Finally, similar to other specialists (Munday et al. 1997), reliance on such a specific biologically derived microhabitat for reproduction could put this and related species at risk if ongoing global change affects the distribution or growth of test-building invertebrates (Doney et al. 2009), even before it affects the Browncheek Blenny directly.

The data presented here document the ontogeny of a microhabitat specialist that follows a "two-step" recruitment pathway leading from planktonic larvae, through a benthic juvenile stage in the open reef environment, to a specialized adult stage that relies on the colonization of vacant invertebrate tests. Through both morphological and ecological life-history tradeoffs, the Browncheek Blenny has come to successfully fill a very specific ontogenetic niche that has allowed it to become one of the most numerically successful species on Gulf of California reefs (Thomson and Gilligan 2002). In the face of seemingly irreversible ecosystem change (Sala and Knowlton 2006), it remains to be seen if these tradeoffs will become a detriment or if these life-history strategies will continue to be successful.

Acknowledgments We thank L. Findley, S. Findley, the ARCS Foundation and SIO CMBC Interdisciplinary Program for support of this research.

Open Access This article is distributed under the terms of the Creative Commons Attribution Noncommercial License which permits any noncommercial use, distribution, and reproduction in any medium, provided the original author(s) and source are credited.

\section{References}

Aburto-Oropeza O, Ezcurra E, Danemann G, Valdez V, Murray J, Sala E (2008) Mangroves in the Gulf of California increase fishery yields. Proc Natl Acad Sci USA 105:10456-10459

Albins MA, Hixon MA (2008) Invasive Indo-Pacific lionfish Pterois volitans reduce recruitment of Atlantic coral-reef fishes. Mar Ecol Prog Ser 367:233-238

Almany GR, Webster MS (2006) The predation gauntlet: early postsettlement mortality in reef fishes. Coral Reefs 25:19-22

Bellwood DR, Wainwright PC, Fulton CJ, Hoey AS (2006) Functional versatility supports coral reef biodiversity. Proc R Soc Lond B 273:101-107

Buchheim JR, Hixon MA (1992) Competition for shelter holes in the coral-reef fish Acanthemblemaria spinosa Metzelaar. J Exp Mar Biol Ecol 164:45-54

Buston P (2003) Forcible eviction and prevention of recruitment in the clown anemonefish. Behav Ecol 14:576-582

Caley MJ, Munday PL (2003) Growth trades off with habitat specialization. Proc R Soc Lond B 270:S175-S177

Caley MJ, St. John J (1996) Refuge availability structures assemblages of tropical reef fishes. J Anim Ecol 65:414-428

Cowen RK (1985) Large scale pattern of recruitment by the labrid, Semicossyphus pulcher: causes and implications. J Mar Res 43:719-742

Dahlgren CP, Eggleston DB (2000) Ecological processes underlying ontogenetic habitat shifts in a coral reef fish. Ecology 81:22272240 
Depczynski M, Bellwood DR (2003) The role of cryptobenthic reef fishes in coral reef trophodynamics. Mar Ecol Prog Ser 256:183191

Depczynski M, Bellwood DR (2006) Extreme plasticity and invariance in vertebrate life history traits: insights from coral reef fishes. Ecology 87:3119-3127

Doherty PJ (1987) The replenishment of populations of coral reef fishes, recruitment surveys, and the problems of variability manifest on multiple scales. Bull Mar Sci 41:411-422

Doherty PJ, Williams DmcB (1988) The replenishment of coral reef fish populations. Oceanogr Mar Biol Annu Rev 26:487-551

Doney SC, Fabry VJ, Feely FA, Kleypas JA (2009) Ocean acidification: the other $\mathrm{CO}_{2}$ problem. Annu Rev Mar Sci 2009 $1: 169-192$

Eggleston DB (1995) Recruitment in Nassau grouper Epinephelus striatus: post-settlement abundance, microhabitat features, and ontogenetic habitat shifts. Mar Ecol Prog Ser 124:9-22

Elliott JK, Mariscal RN (2001) Coexistence of nine anemonefish species: differential host and habitat utilization, size and recruitment. Mar Biol 138:23-36

Elliott JK, Elliott JM, Mariscal RN (1995) Host selection, location, and association behaviors of anemone fishes in field settlement experiments. Mar Biol 122:377-389

Finn MD, Kingsford MJ (2005) Two-phase recruitment of apogonids (Pisces) on the Great Barrier Reef. Mar Freshw Res 47:423-432

Forrester GE (1990) Factors influencing the juvenile demography of a coral reef fish. Ecology 71:1666-1681

Forrester GE, Steele MA (2004) Predators, prey refuges, and the spatial scaling of density-dependent prey mortality. Ecology 85:1332-1342

Futuyma DJ, Moreno G (1988) The evolution of ecological specialization. Annu Rev Ecol Syst 19:207-233

Gerking SD (1994) Feeding ecology of fish. Academic Press, San Diego

Gillanders BM, Able KW, Brown JA, Eggleston DB, Sheridan PF (2003) Evidence of connectivity between juvenile and adult habitat for mobile marine fauna: an important component of nurseries. Mar Ecol Prog Ser 247:281-295

Gonçalves EJ, Faria C (2009) Patterns of microhabitat utilization in blennies. In: Patzner RA, Gonçalves EJ, Hastings PA, Kapoor BG (eds) The biology of blennies. Science, Enfield, pp 405-440

Hastings PA (1986) Habitat selection, sex ratio, and sexual selection in Coralliozetus angelica (Blennioidea: Chaenopsidae). In: Uyeno T, Arai R, Taniuchi T, Matsuura K (eds) Indo-Pacific fish biology. Ichthyological Society Japan, Tokyo, pp 785-793

Hastings PA (1988) Correlates of male reproductive success in the browncheek blenny, Acanthemblemaria crockeri (Chaenopsidae). Behav Ecol Sociobiol 21:95-102

Hastings PA (1991) Flexible responses to predators in a marine fish. Ethol Ecol Evol 3:177-184

Hastings PA (2002) Evolution of morphological and behavioral ontogenies in females of a highly dimorphic clade of blennioid fishes. Evolution 56:1644-1654

Hastings PA, Springer VG (1994) Review of Stathmonotus, with redefinition and phylogenetic analysis of the Chaenopsidae (Teleostei: Blennioidei). Smithsonian Contributions to Zoology 558

Hixon MA, Beets JP (1989) Shelter characteristics and Caribbean fish assemblages; experiments with artificial reefs. Bull Mar Sci 44:666-680

Hixon MA, Jones GP (2005) Competition, predation and densitydependent mortality in demersal marine fishes. Ecology 86:2847-2859

Jones GP (1984) Population ecology of the temperate reef fish Pseudolabrus celidotus Bloch \& Schneider (Pisces: Labridae). I.
Factors influencing recruitment. J Exp Mar Biol Ecol 75:257276

Jones GP (1987) Some interactions between residents and recruits in two coral reef fishes. J Exp Mar Biol Ecol 114:169-182

Kaufman L, Ebersole J, Beets J, McIvor C (1992) A key phase in the recruitment dynamics of coral reef fishes: post-settlement transition. Environ Biol Fish 34:109-118

Kotrschal K, Thompson DA (1986) Feeding patterns in eastern tropical Pacific blennioid fishes (Teleostei: Tripterygiidae, Labrisomidae, Chaenopsidae, Blenniidae). Oecologia 70:367378

Lawlor L, Maynard Smith J (1976) The coevolution and stability of competing species. Am Nat 110:79-99

Lecchini D, Galzin R (2005) Spatial repartition and ontogenetic shifts in habitat use by coral reef fishes (Moorea, French Polynesia). Mar Biol 147:47-58

Leis JM (1991) The pelagic phase of reef fishes: larval biology of coral reef fishes. In: Sale PF (ed) The ecology of fishes on coral reefs. Academic Press, San Diego, pp 183-230

Lin HC, Sanchez C, Hastings PA (2009) Colour variation is incongruent with mitochondrial lineages: cryptic speciation and subsequent diversification in a Gulf of California reef fish (Teleostei: Blennioidei). Mol Ecol 18:2476-2488

Lindquist DG (1985) Depth zonation, microhabitat, and morphology of three species of Acanthemblemaria (Pisces: Blennioidea) in the Gulf of California, Mexico. P.S.Z.N.I: Mar Ecol 6:329-344

Miller PJ (1984) The tokology of gobioid fishes. In: Potts GW, Wootton RJ (eds) Fish reproduction. Academic Press, London, pp 119-153

Munday PL, Jones GP (1998) The ecological implications of small body size among coral-reef fishes. Oceanogr Mar Biol Annu Rev 36:373-411

Munday PL, Jones GP, Caley JM (1997) Habitat specialization and the distribution and abundance of coral-dwelling gobies. Mar Ecol Progr Ser 152:227-239

Nagelkerken I, Roberts CM, van der Velde G, Dorenbosch M, van Riel MC, Cocheret de la Moriniere E, Niehnuis PH (2002) How important are mangroves and seagrass beds for coral-reef fish? The nursery hypothesis tested on an island scale. Mar Ecol Prog Ser 244:299-305

Öhman MC, Munday PL, Jones GP, Caley MJ (1998) Settlement strategies and distribution patterns of coral-reef fishes. J Exp Mar Biol Ecol 225:219-238

Robinson BW, Wilson DS (1998) Optimal foraging, specialization, and a solution to Liem's paradox. Am Nat 151:223-235

Sala E, Knowlton N (2006) Global marine biodiversity trends. Annu Rev Environ Resour 31:93-122

Sale PF (1977) Maintenance of high diversity in coral reef fish communities. Am Nat 111:337-359

Sale PF (1980) The ecology of fishes on coral reefs. Oceanogr Mar Biol Annu Rev 18:367-421

Sale PF, Doherty PJ, Eckert GJ, Douglas WA, Ferrell DJ (1984) Large scale spatial and temporal variation in recruitment to fish populations on coral reefs. Oecologia 64:191-198

Shulman MJ (1984) Resource limitation and recruitment patterns in a coral reef fish assemblage. J Exp Mar Biol Ecol 74:85-109

Shulman MJ (1985) Recruitment of coral reef fishes: effects of distribution of predators and shelter. Ecology 66:1056-1066

Shulman MJ, Ogden JC (1987) What controls tropical reef fish populations: recruitment or benthic mortality? An example in the Caribbean reef fish Haemulon flavolineatum. Mar Ecol Prog Ser 39:233-242

Smith-Vaniz WF, Jelks HL, Rocha LA (2006) Relevance of cryptic fishes in biodiversity assessments: a case study at Buck Island Reef National Monument, St. Croix. Bull Mar Sci 79:17-48 
Stephens JS Jr (1963) A revised classification of the blennioid fishes of the American family Chaenopsidae. Univ Calif Publ Zool 68:1-165

Sweatman HPA (1983) Influence of conspecifics on choice of settlement sites by larvae of two pomacentrid fishes (Dascyllus aruanus and $D$. reticulatus) on coral reefs. Mar Biol 75:225-229

Sweatman HPA (1985) The influence of adults of some coral reef fishes on larval recruitment. Ecol Monogr 55:469-485

Thomson DA, Gilligan MR (2002) Rocky shore fishes. In: Case TJ, Cody ML, Ezcurra E (eds) A new island biogeography of the Sea of Cortéz. Oxford University Press, Oxford
Thresher RE (1984) Reproduction in reef fishes. T.F.H. Publishers, Neptune City

Tupper M, Juanes F (1999) Effects of a marine reserve on recruitment of grunts (Pisces: Haemulidae) at Barbados, West Indies. Environ Biol Fish 55:53-63

Wellington GM (1992) Habitat selection and juvenile persistence control the distribution of two closely related Caribbean damselfishes. Oecologia 90:500-508

Williams DMcB, Sale PF (1981) Spatial and temporal patterns of recruitment of juvenile coral reef fishes to coral habitats within One Tree Lagoon, Great Barrier Reef. Mar Biol 65:245-253 